Wojciech Domozych*

Wojciech Łukasz Dragan*

\title{
Genetic and Environmental Basis of the Relationship Between Dissociative Experiences and Cloninger's Temperament and Character Dimensions - Pilot Study
}

\begin{abstract}
Dissociation is commonly regarded as a disruption in the normally integrated functions of memory, knowledge, affect, sensation or behavior. The present study utilized behavioral genetics' methodology to investigate genetic and environmental basis of the relationship between dissociation and Cloninger's temperament and character traits. A sample of 83 monozygotic and 65 dizygotic twins were administered self-report measures which assessed dissociative experiences along with personality dimensions. Significant correlations and high loads of common genetic variance between dissociative experiences and personality traits of novelty seeking, self-directedness, cooperativeness and selftranscendence were identified. Heritability of dissociative experiences was estimated at $62 \%$. The study shows that there exists a considerable amount of genetic variance overlap between dissociation and personality dimensions. It also supports the hypothesis that propensity to dissociate is highly heritable.
\end{abstract}

Key words: dissociation, temperament, character, behavior genetics, pathway analysis

Dissociation has been defined as a disruption of normally integrated functions of perceptual, emotional, and memory systems (American Psychiatric Association [APA], 2000). It is considered to play an important defensive role in situations when an individual experiences a traumatic event that is too difficult to cope with emotionally. Such mechanism would cause detachment of emotional and cognitive functions involved in processing those psychologically overwhelming experiences. A deeper understanding of its genetic and environmental underpinnings would help to explain how facing traumatic situations can lead to the Post-Traumatic Stress Disorder (PTSD) and perhaps to develop effective therapies.

The construct of dissociation itself still is a centre of a yet unresolved discussion, whether its nature is dimensional or typological. Some empirical research point to a typological model which divides the universe of dissociative experiences into relatively mild non-pathological symptoms observed among the whole population (e.g. absorption or absentmindedness) and more severe states, indicative of pathology, such as depersonalization, derealization, amnesia and multiple personality (Putnam,
1997; Waller, Putnam, \& Carlson, 1996). From this point of view it would not seem superfluous to determine the degree to which those two types of dissociation are influenced by the common and by the separate factors. In contrary, other researchers suggest that it would be more adequate to apply a dimensional model in which dissociative experiences are assumed to be continuously distributed throughout the population. Results supportive of this hypothesis were obtained by the research on the Dissociative Experiences Scale (DES; Bernstein \& Putnam, 1986).

Behavior genetics is a field of study that combines statistics with genetic and behavioral sciences to determine extent to which genetic and environmental factors contribute to the overall phenotypic variance of psychological dimensions (e.g. personality features) in different populations. A phenotype is defined as a final result of genetic and environmental influences that is apparent in a certain trait or behavior. The methodology of behavior genetics bases on two basic assumptions. In the first of them it is stated that all of the differences among individuals who belong to a certain population are determined, at variable proportion, by genetic and non-

\footnotetext{
* The Interdisciplinary Centre for Behavioural Genetics Research, Faculty of Psychology, University of Warsaw 
genetic factors. The genetic factor can be divided into additive and non-additive. The additive factor is influenced by assortative (selective) mating of parents and random parents-children genetic transmission which to some extent is shaped by natural selection. The non-additive factor pertains to effects that are due to single-gene dominance deviations as well as epistatic interactions between different genes. Then, the environmental factor may be of shared or unique (non-shared) nature. Shared environment increases resemblance within the same family, while, conversely, unique environment decreases it, mostly due to individual experiences gained exclusively by each family member throughout life, but also because of genotypeenvironment interactions and correlations, as well as errors of measurement. All the main sources of phenotypic variance as outlined in the current model (Plomin, DeFries, McClearn, \& McGuffin, 2008) are illustrated on Figure 1.

Figure 1. A scheme of the sources of phenotypic variance

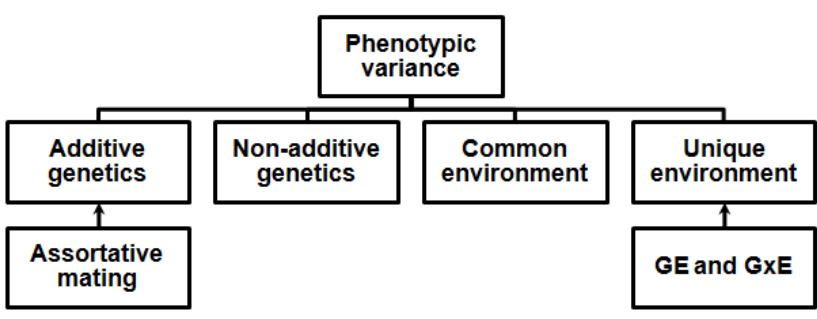

Note. GE means correlation between genotype and environment, while GxE stands for their interaction.

The concept of heritability is central to the field of behavior genetics. It refers to a contribution of the genetic factor to the total phenotypic variance in a certain population, expressed as a percentage of it. More precisely, heritability is "a proportion of phenotypic variance that can be attributed to the genetic differences between individuals" (Plomin et al., 2008). It is then easy to see that estimation of heritability of a feature is equivalent to calculating the extent to which this feature is influenced environmentally. Moreover, multivariate behavior-genetic models may be utilized to examine the structure of genetic and environmental correlations between several dimensions (Neale \& Cardon, 1992).

Both genetic and environmental factors have been suggested as underpinnings for development of dissociative experiences. The results of existing research in behavioral genetics of dissociation are inconsistent. Some of them indicate that it is highly heritable (Becker-Blease et al., 2004; Jang, Paris, Zweig-Frank, \& Livesley, 1998; Pieper, Out, Bakermans-Kranenburg, \& van Ijzendoorn, 2011), while another work excludes any genetic influence (Waller \& Ross, 1997).

That those findings remain contradictory should be considered as supportive for a well-established view that the most important role in development of dissociative tendencies is played by the environmental factors. Studies that have hitherto explored the environmental- only etiology of dissociation point to abusive childhood experiences, especially sexual, physical and emotional maltreatment but also caregiver neglect and betrayal. This has been demonstrated in adults (Coons, Bowman, \& Milstein, 1988; Putnam, Gurof, Silberman, Barbar, \& Post, 1986), adolescents (Bowman, Blix, \& Coons, 1985; Dell \& Eisenhower, 1990; Hornstein \& Putnam, 1992) and children (Coons, 1994; Fagan \& McMahon, 1984). However, the most recent study showed that the largest levels of dissociation are observed in the foster children who had experienced all types of abuse or only the physical abuse (Hulette, Freyd, \& Fisher, 2011). Those proved to be significantly higher than the magnitude of dissociative experiences in the groups of children who had been sexually abused or neglected by their caregivers. On the other hand, Braun and Sachs suggested that there may exist a "natural, inborn capacity to dissociate which could determine potential magnitude of dissociative symptoms triggered by specific environmental circumstances" (Braun \& Sachs, 1985). Not only does this view seem to receive support from research conducted per the behavioral approach, which is indicative of dissociation's heritability, but it also fits well into the results obtained from molecular analyses. The latter point in the first order to the serotonin transporter gene promoter polymorphism (5-HTTLPR), whose role in the etiology of dissociation was discovered by Pieper with her team (Pieper et al., 2011). Moreover, it has been shown that in women with a history of sexual or physical abuse this polymorphism is related to novelty seeking (Steiger, Richardson, \& Joober, 2007). Another suggested direction of research is connected with the relationship between PTSD symptoms and the dopamine receptor type 4 (DRD4) polymorphism (Dragan \& Oniszczenko, 2009). What is interesting and promising about this location within human genome is that a number of links between the DRD4 polymorphisms and novelty seeking have been discovered (Benjamin et al., 1996; Ebstein et al., 1996; Noble et al., 1998). However, other studies (e.g., Strobel, Spinath, Angleitner, Riemann, \& Lesch, 2003) and, more importantly, a meta-analysis of them (Munafo, Yalcin, Willis-Owen, \& Flint, 2008) have failed to demonstrate any association between novelty seeking and the variable number tandem repeat (VNTR) DRD4 polymorphism that has been linked to the PTSD symptoms by Dragan and Oniszczenko (2009). Still, in the same work Munafo with colleagues reported a significant relationship between this temperament trait and another DRD4 polymorphism $(-521 \mathrm{C} / \mathrm{T})$.

Dissociation has been examined with regard to its simple correlations with many different personality traits: the Big Five dimensions (Ruiz, Pincus, \& Ray, 1999), Revised Dimensions of Temperament Survey (DOTS-R) and the Rusalov Structure of Temperament Questionnaire (STQ) temperamental features (Beere \& Pica, 1995), Cloninger's personality dimensions measured by the Revised Temperament and Character Inventory (TCI-R; Evren, Sar, \& Dalbudak, 2008), dissociative mental disorders (including PTSD), hypnotic susceptibility (van Ijzendoorn \& Schuengel, 1996) and schizotypy (Pope \& Kwapil, 2000; Merckelbach, Rassin, \& Muris, 2000). All of these works show that more extensive and thorough research on relationships between 
the dissociative experiences and personality should be undertaken. Therefore, in the present study genetic and environmental factors that influence both personality traits and dissociation are chosen to be the main object of examination. Continuation of the research on dissociation and its genetic and environmental basis also seems to be more than necessary, because this area of psychology of personality and individual differences still remains underexplored.

In the presented work our team decided to employ the original Cloninger's TCI inventory as a measure of temperament and character traits, because it is directly related to the psychobiological model of personality in which certain neurotransmitter systems are assumed to underpin some of the temperamental features (Cloninger, Svrakic, \& Przybeck, 1993). Not only does this inventory allow its users to include testable hypotheses regarding genetic and environmental basis of different areas of temperament and character, but it also, in case of positive findings among correlations with other dimensions, renders the search of genetic candidates for molecular analyses a lot more tractable. Notably, it has been shown by Mardaga \& Hansenne (2007) that the temperamental dimensions of TCI share substantial correlations with Gray's behavioral inhibition/activation systems (BIS/BAS; Gray, 1970).

The Cloninger's psychobiological model divides the structure of personality into a more genetically determined temperament, whose features stem from functioning of the procedural memory, and a more environmentally influenced character, which is assumed to be closely related to the declarative memory system. The temperament traits in this model, which are "involved in presemantic perceptual processing and encoding of concrete visuospatial structural information and affective valence" (Gillespie, Cloninger, Heath, \& Martin, 2003) consist of: novelty seeking (NS), harm avoidance (HA), reward dependence (RD) and persistence (PS). According to the authors, the first three are supposed to have separate biological underpinnings: dopamine, serotonin and noradrenalin neurotransmission systems, respectively. No theoretical assumptions has been made regarding the last feature. The character traits are dependent on social and cognitive development and include: self-directedness (SD), cooperativeness (CO) and self-transcendence (ST). The temperament traits are to be considered as the primary personality features on the basis of which secondary (yet highly independent with regard to environmental sources of variance) character traits develop. This hierarchical outlook on personality traits is supported by the multivariate analyses of convergent and discriminant TCI's validity (Ando et al., 2002). On the other hand, some evidence suggests not only environmental but also partial genetic independence of character from temperament (Gillespie et al., 2003).

In the present study we evaluated the influence of genetic and environmental factors on the relationship between Cloninger's temperament and character traits and dissociative experiences. Although we chose to explore the data rather than test specific hypotheses, there are certain expectations related to this study which arise from the previous research that points to manifold connections between dissociation and the TCI dimensions. Thus, NS and HA are expected to be genetically correlated with the propensity to dissociate, as the DRD4 polymorphism appears to be related to the PTSD symptoms and the 5-HTTLPR polymorphism has been directly linked with dissociation. Another hypothesis would involve all of the character traits, since it has been shown that people with low self-directedness and cooperativeness along with high self-transcendence (a structure typical of persons with mental disorders) tend to be more schizotypic, hypnotizable and also more prone to absorption (Laidlaw et al., 2005). Moreover, Szekely et al. (2010) discovered a significant association between the trait of hypnotizability and the dopamine metabolite catechol-O-methyltransferase (COMT) Val158Met single nucleotide polymorphism (SNP, rs4680), which opens up the possibility that the dopaminergic system may play a crucial role in development of dissociation not only through high level of NS, but also through the functional relation between dopamine level in the prefrontal cortex (PFC) and efficiency of the cognitive functions.

\section{Method}

The study utilizes one of the most frequently applied method for behavior genetics - a twin study. Basically, its aim is to determine existence of genetic underpinnings of certain features or behaviors by comparing their correlations in separate groups of monozygotic and dizygotic twins reared together. If the correlation coefficient calculated for the former is distinctly higher than the one calculated for the latter, a non-zero contribution of genetic factors to the variance of the measured variables is to be suspected.

The above-described method is based on a few assumptions (Plomin et al., 2008):

- $\quad$ MZ twins are genetically identical, whereas DZ twins share $50 \%$ of their genotypes,

- any observed differences in the behavior characteristics of $\mathrm{MZ}$ twins stem from the environmental factors only, whereas in DZ twins both genetic and environmental factors account for all such differences,

- $\quad$ similarities determined by environment are the same among both MZ and DZ twins,

- parents' mating occurs at random with regard to the analyzed behavioral traits.

The aforementioned assumptions were often criticized for their putative counterfactuality, especially the one stating environmental equality. On the other hand, it is a well-established view, that the proportions or distributions posited through those assumptions are roughly equal to the actual ones, hence overall the method ought to be useful (Plomin et al., 2008).

\section{Participants}

The eligible twins in the approximate number of 1000 were chosen on the basis of the sampling frame, a Polish twin database that has been accumulated by the Interdisciplinary Centre for Behavioural Genetics Research (ICBGR). The full sets of questionnaires were sent to all the eligible twins via mail. 152 pairs of those twins (each 
of the same gender) filled them in and sent back to the indicated address. Four pairs have been excluded from the analysis due to extremely high rates of item nonresponse. Out of the remaining 148 pairs 105 were feminine and 43 were masculine in the age ranging from 13 to 66 with the mean being equal to 24.38 and standard deviation - to 8.24 . Out of 141 pairs who provided their birth year $103(73 \%)$ belonged to the youngest age group (13-25 years old), $36(26 \%)$ - to the middle-aged group, and 2 pairs $(1 \%)$ were the oldest twins having 56-66 years old. Importantly, 7 twin pairs (5\%) were young adolescents (13-15 years) while 16 pairs $(11 \%)$ were $16-18$ years old.

Zygosity was determined by the means of the Twins Physical Resemblance Questionnaire (TPRQ; Oniszczenko \& Rogucka, 1996). This measure contains several questions about twins' morphological characteristics and psychical resemblance, as well as questions about the degree to which they had been confused with each other by parents, siblings and friends. Each twin is instructed to describe him- or herself in comparison to the brother or sister but without any communication between them. Out of these items six are used to construct a discriminative function which separates monozygotic twins from dizygotic twins. Its validity, expressed as the percentage of correct assignments, proved to be as high as $94 \%$. In the current study, out of the 148 twin pairs who were included in the analysis 83 have been diagnosed as monozygotic and 65 as dizygotic.

Prior to the investigation every participant had been informed about the nature of the study and gave his or her informed consent in writing. The research project was accepted by the Ethics Commission at the Faculty of Psychology, University of Warsaw.

\section{Measures}

Dissociative experiences were evaluated with the second version of DES (DES-II; Carlson \& Putnam, 1993) is a self-report scale which comprises of 28 item, each of them being scored from 0 to 100 with a step of 10 . Any number stands for degree to which a participant experienced manifold dissociative symptoms in daily life: amnesia, depersonalization, derealization and absorption. It has been suggested than one of the items is inappropriate for same-sex twin subjects, because it pertains to situations when people called them by another name or insisted that they met them before (Pieper et al., 2011). However, a possibility cannot be ruled out that higher frequency of such incidents among twins might interact in some way with their propensity to dissociate (i.e. bolster or reduce it). Moreover, scores on this particular item, albeit higher than average - contrary to what would have been expected on the premise of the descriptive statistics from the general population (Ross, 1996) - were not distinctly higher than their counterparts for a half of the remaining items. Therefore it was not excluded from further proceedings. In the light of the psychometric research accumulated so far (Ross, 1996; van Ijzendoorn \& Schuengel, 1996) DES-II proves to be a valid and highly reliable instrument with Cronbach's alpha being equal to .93 and a high test-retest stability $(r=.84)$. Unfortunately, there is no available reliability data regarding its Polish version, thus
Cronbach's alpha coefficient was derived off the present twin sample to serve an ad-hoc diagnostic purpose. It was equal to .94 , so it can be said that in our sample the Polish version of DES-II has proved to have excellent internal consistency, which also happens to be very close to the original version. However, we admit that there is a lack of any data that could be supportive of the validity of Polish DES, as the design of the present study did not empower us to provide any compelling evidence thereof.

To measure temperament and character traits the Polish version of TCI was used (Hornowska, 2003). This tool had been constructed to operationalize the psychobiological model of personality (Cloninger et al., 1993). It consists of seven independent scales, each of them measuring one of the hypothesized temperament and character dimensions. It is a 240-item, self-report, forced-choice measure.

\section{Statistical analyses}

Although due to unreturned questionnaires and item nonresponse, some data on dissociative experiences and TCI dimensions were incomplete, the total percentage (after exclusion of 4 subjects who merely started filling in the sheets) of missing data was equal only to $0.34 \%$. Thus, just the most basic means of imputation have been used. The missing values in TCI positions were changed to halfpoints, while in DES-II they were replaced by the mean of the remaining filled positions. Afterwards, we checked the multivariate distributions of all included dimensions in order to identify those whose kurtosis measured by the $z$ statistic exceeds the threshold of 5 indicating of an early departure from normality (see: Byrne, 2010). Only distribution of the DES-II scores were not even roughly equal to normal. Therefore they have been log-transformed, which effectively solved the problem of non-normality. We then performed the multivariate behavioral genetic analyses to determine the level in which additive genetics (A), shared environment (C) and unique environment plus error of measurement (E) contribute to the variance and covariance among the included dimensions, as well as to examine the genetic and environmental correlations between dissociation and TCI traits. Structural equation modeling and maximum likelihood estimation were used to fit $\mathrm{ACE}, \mathrm{AE}$ and $\mathrm{CE}$ Cholesky models with different numbers of independent factors (2 to 8) as described by Neale and Cardon (1992). We compared the models in terms of the Akaike Information Criterion (AIC) and the root mean square error of approximation (RMSEA) in order to choose the one that has the closest fit-to-data. On the basis of the best model genetic and environmental correlations were estimated along with their 95\% confidence intervals. All analyses were performed in SAS ${ }^{\circledR}$ University Edition with an open-source add-on called SASPairs (http://psych. colorado.edu/ carey/SASPairs/).

\section{Results}

Descriptive statistics for DES-II and TCI scores are presented in Table 1. The mean score of dissociative experiences was comparable to other nonclinical samples, 
in which this statistic usually varies from 10 to 20 (Ross, 1996). The distribution of DES scores was also typically left-skewed with only $15.2 \%$ participants scoring 30 or more. TCI scores did not exceed the typical values demonstrated in the Polish general population (Hornowska, 2003). Heritability od dissociation was estimated at $64 \%$, while most temperament traits proved to be consistently less heritable $(35-50 \%)$ than all character traits $(62-65 \%)$. Of note is that based on the current sample the temperament trait of harm avoidance was not heritable at all.

Multivariate pathway analyses included 21 distinct models: 7 models nested within each other in an incremental manner as per the variable number of Cholesky factors used ( 2 to 8 ) for each of the 3 select specification families - ACE, AE and CE. From each specification family the best-fit model was chosen and then 3 candidate models were compared in terms of AIC and RMSEA statistics. Those 3 models are summarized in Table 2 .

The AE model with 7 independent Cholesky factors yielded the best fit-to-data. Therefore, for the purpose of calculating genetic and environmental correlations between variables, estimates from this model were used. All correlation coefficients, percentages of common phenotypic, genetic and environmental variance between dissociation and TCI dimensions along with their 95\% confidence intervals are presented in Table 3 . The

Table 1. Medians, means, standard deviations, ranges and heritability estimates $\left(h^{2}\right)$ with $95 \%$ confidence intervals from best-fit univariate models for the TCI and DES-II scales $(\mathrm{N}=\mathbf{2 9 6})$

\begin{tabular}{lcccc|cc}
\hline \multicolumn{1}{c}{ Scale } & Median & Mean & SD & Range & Model & $\mathbf{h}^{2}(\mathbf{9 5} \% \mathbf{C I})$ \\
\hline NS & 19.5 & 19.98 & 5.90 & $6-38$ & AE & $.50(.35-.65)$ \\
\hline HA & 15.0 & 15.25 & 6.93 & $0-34$ & CE & .00 \\
\hline RD & 16.0 & 15.39 & 3.59 & $3-23$ & AE & $.44(.28-.61)$ \\
\hline PS & 4.0 & 4.43 & 1.88 & $0-8$ & AE & $.35(.20-.50)$ \\
\hline SD & 28.0 & 27.05 & 7.81 & $6-43$ & AE & $.65(.48-.81)$ \\
\hline CO & 33.0 & 30.93 & 5.99 & $11-41$ & AE & $.64(.47-.81)$ \\
\hline ST & 16.0 & 16.01 & 6.18 & $1-30$ & AE & $.62(.46-.78)$ \\
\hline DES-II & 12.8 & 17.32 & 14.05 & $0-76$ & AE & $.64(.48-.80)$ \\
\hline
\end{tabular}

Note. NS - novelty seeking; HA - harm avoidance; RD - reward dependence; PS - persistence; SD - self-directedness; $\mathrm{CO}$ - cooperativeness; ST - self-transcendence.

Table 2. Summary of multivariate ACE model-fitting results

\begin{tabular}{lccccc}
\hline \multicolumn{1}{c}{ Model } & $\boldsymbol{\chi}^{\mathbf{2}}$ & $\mathbf{d f}$ & $\mathbf{p}$ & AIC & RMSEA \\
\hline 3-factor ACE & 236.987 & 204 & .0565 & -171.013 & .001 \\
\hline 7-factor AE & $\mathbf{2 1 7 . 4 4 6}$ & $\mathbf{2 0 1}$ & $\mathbf{. 2 0 2 7}$ & $\mathbf{- 1 8 4 . 5 5 4}$ & $\mathbf{. 0 0 0}$ \\
\hline 7-factor CE & 259.373 & 201 & .0034 & -142.627 & .001 \\
\hline
\end{tabular}

Note. The model with the best fit-to-data is in bold. A - additive genetic factors; C - shared environmental factors; $\mathrm{E}$ - unique environmental factors and error of measurement.

Table 3. Phenotypic $\left(r_{p}\right)$, genetic $\left(r_{g}\right)$ and environmental $\left(r_{e}\right)$ correlations and communalities based on the 7-factor AE Cholesky model

\begin{tabular}{llllccc}
\hline \multirow{2}{*}{ Trait } & \multicolumn{2}{c}{ Correlations with DES-II } & \multicolumn{2}{c}{$\%$ of shared variance (with 95\% CI) } \\
\cline { 2 - 6 } & $\mathbf{r}_{\mathbf{p}}$ & $\mathbf{r}_{\mathbf{g}}$ & $\mathbf{r}_{\mathrm{e}}$ & Phenotypic & Genetic & Environmental \\
\hline NS & $.168^{* *}$ & $.489^{* *}$ & $-.254^{* *}$ & $2.81(.48-7.09)$ & $23.93(11.42-41.02)$ & $6.44(1.93-13.60)$ \\
HA & .081 & .020 & $.166^{* *}$ & & & $2.77(.22-8.20)$ \\
RD & .063 & .060 & .069 & & & $4.41(.49-12.25)$ \\
PS & .005 & -.238 & $.210^{* *}$ & & & \\
SD & $-.379^{* *}$ & $-.551^{* *}$ & -.085 & $14.40(6.41-25.57)$ & $30.41(13.14-54.81)$ & $4.32(.70-11.03)$ \\
CO & $-.206^{* *}$ & $-.463^{* *}$ & $.208^{* *}$ & $4.25(.43-12.01)$ & $21.43(6.20-45.83)$ & $4.33(.78-10.76)$ \\
ST & $.337^{* *}$ & $.414^{*}$ & $.208^{* *}$ & $11.35(1.63-29.83)$ & $17.17(.76-54.97)$ & \\
\hline
\end{tabular}

Note. Correlations significant on .05 and .01 level have been labeled ${ }^{*}$ and ${ }^{* *}$ respectively. Cells with non-significant values of shared proportion of variance have been left blank. 
confidence intervals are based on the standard errors of the unstandardized path coefficients, calculated using a wellestablished formula for standard error propagation in sums and products of uncorrelated statistics in small samples (Baron \& Kenny, 1986; MacKinnon \& Dwyer, 1993).

Out of 21 correlation coefficients only 8 remained non-significant. With regard to the phenotypic correlations, dissociation was positively related to NS and ST, while negative $r$ values were observed for SD and CO. Simple correlations of DES-II scores with SD and ST also proved to be substantially stronger than with NS and CO. The pattern of the genetic correlations was highly similar to that of the phenotypic correlations. In this case coefficients for NS, SD and CO were the highest and most significant. Five of the environmental correlations reached the .01 level of statistical significance.

The shares of the common genetic variance between TCI dimensions and dissociative experiences were substantially higher than those observed for the common environmental variance. It is worth noting that as per the $95 \%$ confidence intervals the significant genetic communalities across DES-II score and the traits of NS, SD and $\mathrm{CO}$ are highly unlikely to be lower than 6-13\% while, conversely, they may be as high as $41-55 \%$.

The sum of squared genetic correlations of dissociation with the Cloninger's dimensions plus its own genetic portion of variance equaled $62 \%$. This is the estimate of dissociative experiences' heritability provided by the 7-factor AE Cholesky model.

\section{Discussion}

In the present study we utilized a twin study behavioral approach to examine genetic and environmental influences on the relationship between Cloninger's personality dimensions and dissociative experiences. The results indicate that the pattern of variances and covariances among the included variables is best explained by 7 independent additive genetic factors, unique environment and error of measurement. TCI dimensions that were found to be least correlated with dissociative experiences were HA and RD, whereas NS and PS showed high environmental communalities (also genetic for NS). This pattern may suggest a possibility that Gray's behavior activation system (BAS) could be part of the neurobiological underpinnings of dissociation, as opposed to the behavior inhibition system (BIS).

What contributes to the considerable phenotypic overlap between dissociation and the traits of novelty seeking, self-directedness, cooperativeness and selftranscendence are mostly genetic factors. However, a significant amount of environmental influence is present in the NS-dissociation relationship, pointing to the possibility that shared environmental factors exist for both dimensions. This study also replicates previous findings which identified the AE model as the one with the best fit-to-data and produced an estimate of dissociation's heritability that was substantially exceeding half of the total phenotypic variance in general population.
Taken the above into consideration, there seem to emerge two alternative yet not contradictory hypothetical mechanisms which to some extent could be responsible for bolstering dissociative capacity. The first of them concentrates on the temperamental determinants of behavior, mainly on the possible connections between dissociation, PTSD and the feature of novelty seeking. Not only did many studies lead to the discovery of significant dissociation-NS (Evren et al., 2008) and PTSD-NS phenotypic correlations (Richman \& Frueh, 1997), but they have also provided some support for the present findings regarding genetic correlations by linking several dopaminerelated polymorphisms to novelty seeking (Benjamin et al., 1996; Ebstein et al., 1996; Munafo et al., 2008; Noble et al., 1998) and PTSD (Dragan \& Oniszczenko, 2009). Although not all of the results are consistent with each other, they seem to indicate that neurobiological underpinnings of dissociation are to be looked for in the dopamine system. Therefore, significant phenotypic and genetic correlations of novelty seeking with dissociative experiences call for further analyses which would employ molecular techniques in order to find associations between those experiences and the DRD4 polymorphisms. However, if the dissociationNS relationship is mediated somehow by dopamine, any molecular research should include possible environmental moderators, since the present study indicates that these two dimensions correlate environmentally with each other stronger than what is observed for any other Cloninger's personality trait.

The second hypothetical mechanism would be connected with cognitive functioning of an individual. It is supposedly related to the trait of hypnotic susceptibility, which is thought to share many clinical and experimental features with dissociation (Carlson \& Putnam, 1989). Links have been demonstrated between homovanilic acid (HVA), a cerebrospinal fluid dopamine metabolite, and both hypnotizability (Spiegel \& King, 1992) and dissociation (Demitrack et al., 1993). The finding of Spiegel and his colleague led them to a conclusion that neurotransmission activity within dopaminergic system, particularly involving functional activation of frontal lobe pathways, may underpin generation of hypnotic phenomena. This view is strongly supported by the recent findings of Szekely et al. (2010), who successfully associated the trait of hypnotic susceptibility with gene coding for COMT, another metabolite which is responsible for degradation of dopamine. Several studies demonstrated that COMT is an important factor in modulating the dopamine level in PFC (e.g., Malhotra et al., 2002) but to date there are no data on COMT-dissociation relationship. However, more links seem to exist between dissociative experiences and hypnotizability than just genetic and biochemical associations. Both phenomena are supposed to be closely related to the executive functions. Dopamine levels in PFC moderate cognitive performance in challenging hypnotic suggestion, while the same factor may influence dissociative capacity. Such an analogy would be compatible with some theoretical assumptions. Hilgard (1986) proposed the neodissociation model of hypnotic experience, 
according to which hypnosis might interfere with executive functions and thus influence activity of many hierarchically structured cognitive subsystems. On the other hand, Kennedy et al. (2004) suggested that dissociation may function as an important mechanism in development of PTSD, since it appears to be responsible - through executive functions - for inhibition of normal association processes that pertain to extremely threatening memories. Moreover, dissociation has been extensively researched with relation to borderline personality disorder (BPD) by Korzekwa et al. (2009), who presented a view that dissociation serves as a suppressing factor for excessive emotional arousal which stems from the amygdala.

The apparent relationship between dissociation and hypnotic susceptibility seems to support the pattern of correlations obtained by our team for Cloninger's character features. Laidlaw et al. (2005) demonstrated that the highest levels of both hypnotizability and absorption (a mild dissociative symptom) are observed in those individuals who score low on the SD and CO scales and high on the ST scale.

In the present study we showed that $\mathrm{SD}$ and $\mathrm{CO}$ correlate negatively and ST correlates positively with the propensity to dissociate. Interestingly, a very strong association (with $5.43 \%$ contribution) between ST and the DRD4 polymorphism has also been discovered (Comings, Saucier, \& MacMurray, 2002). Also from a theoretical viewpoint ST scale, which measures one's ability to move outside oneself, fits well into the concept of dissociation. Moreover, while NS is not as strongly phenotypically correlated with dissociative experiences as SD or ST, its genetic correlation remains second-largest, being only slightly lower than that of the ST scale. Since both of these features have been associated with the same dopaminerelated polymorphism, it would be interesting to inquire whether a similar link can be established with dissociative capacity.

There seem to exist a number of different traces to follow in further research. Firstly, it would not seem superfluous to seek a big-sample replication of the most apparent correlations between dissociation and Cloninger's character traits. Additional goals of such a continuation study could be to explore the genetic and environmental basis of these associations using molecular analyses as well as measures of relevant psychological features (such as hypnotic susceptibility and emotion regulation) and/or neurobiological variables (such as executive functions of PFC and reactivity of the amygdala). Secondly, Steiger et al. (2007) associated the 5-HTTLPR polymorphism with novelty seeking, while Pieper and colleagues (2011) did the same with regard to dissociative experiences. These findings indicate that the serotoninergic system may be involved in development of dissociation. However, our study does not support the hypothesis of its relationship with harm avoidance as a trait linked to serotonin neurotransmission. It would be interesting to repeat analysis of genetic and environmental correlations between dissociation and temperamental traits using BIS/BAS scale in search of a more parsimonious model compared to 7-factor TCI-based model. Thirdly and tentatively, some neurobiological evidence suggests that noradrenaline may be related to dissociation (Simeon et al., 2007) and possibly underlie the dissociative mechanism of dampening emotional arousal that would normally be induced with traumatic memories (Korzekwa et al., 2009). Then again, this particular hypothesis remains completely unsupported by our findings, because according to them there does not seem to be any genetic overlap between dissociation and reward dependence, a feature that is supposedly constituted mostly by the noradrenergic system.

The present work has several limitations. First and foremost, the studied sample is small, what makes the statistical power for the obtained effects too weak and the confidence intervals for the estimates too long to provide any conclusive evidence. Moreover, this sample may not be sufficiently representative of the general Polish population, mostly due to a likely non-random recruitment of participants. This might raise concerns around the external validity of the research and is incidentally reflected by the substantial overrepresentation of female twins as well as by $16 \%$ of the twins being adolescents at the two different stages of personality development, which might render TCI results incongruent (Januszewski, 2009). Then again, the feminine prevalence may play no significant role in biasing the results obtained from our sample, because similar correlation patterns were observed between male vs. female dissociative experiences and Cloninger's character traits (Grabe, Spitzer, \& Freyberger). However, it cannot go unnoticed that the ratio of $\mathrm{MZ}$ twin to DZ twins in the analyzed sample remains inverted in relation to the general population, where DZ twins are highly prevalent. This sampling artifact might itself indicate that willingness to participate in a study is heritable, but more importantly it may lead to an overall biased model estimation. All of the above should be taken into consideration and lead to a cautious approach to our findings. However, we believe that their surprisingly high coherence with many previous studies in different fields do warrant future replications on larger and more representative samples, as well as further research in the indicated directions by the means of molecular genetics as well as other psychological and neurobiological approaches.

\section{References}

American Psychiatric Association. (2000). Diagnostic and statistical manual of mental disorders (4th ed., text rev). Washington, DC: Author.

Ando, J., Ono, Y., Yoshimura, K., Onoda, N., Shinohara, M., Kanba, S., \& Asai, M. (2002). The genetic structure of Cloninger's seven-factor model of temperament and character in a Japanese sample. Journal of Personality, 70(5), 583-609.

Baron, R.M., \& Kenny, D.A. (1986). The moderator-mediator variable distinction in social psychological research: Conceptual, strategic, and statistical considerations. Journal of Personality and Social Psychology, 51, 1173-1182.

Becker-Blease, K., Deater-Deckard, K., Eley, T., Freyd, J.J., Stevenson, J., \& Plomin, R. (2004). A genetic analysis of individual differences in dissociative behaviors in childhood and adolescence. Journal of Child Psychology and Psychiatry, 45(3), 522-532. 
Beere, D., \& Pica, M. (1995). The predisposition to dissociate: The temperamental traits of flexibility/rigidity, daily rhythm, emotionality and interactional speed. Dissociation, 8(4), 236-240.

Benjamin, J., Li, L., Patterson, C., Greenberg, B.D., Murphy, D.L., \& Hamer, D.H. (1996). Population and familial association between the D4 dopamine receptor gene and measures of novelty seeking. Nature Genetics, 12, 81-84.

Bernstein, E.M., \& Putnam, F.W. (1986). Development, reliability, and validity of a dissociation scale. Journal of Nervous and Mental Disease, 174, 727-735.

Bowman, E.S., Blix, S., \& Coons, P.M. (1985). Multiple personality in adolescence: Relationship to incestual experiences. American Academy of Child Psychiatry, 24, 109-114.

Braun, B.G., \& Sachs, R.G. (1985). The development of multiple personality disorder: Predisposing, precipitating, and perpetuating factors In R.P. Kluft (Ed.), Childhood antecedents of multiple personality disorder. Washington, DC: American Psychiatric Press.

Byrne, B.M. (2010). Structural equation modelling with AMOS: Basic concepts, applications, and programming. New York: Routledge.

Carlson, E.B., \& Putnam, F.W. (1989). Integrating research on dissociation and hypnotizability: Are there two pathways to hypnotizability? Dissociation, 2, 32-38.

Carlson, E.B., \& Putnam, F.W. (1993). An update on the dissociative experiences scale. Dissociation, 6, 16-27.

Cloninger, C.R., Svrakic, D.M., \& Przybeck, T.R. (1993). A psychobiological model of temperament and character. Archives of General Psychiatry, 50, 975-990.

Comings, D.E., Saucier, G., \& MacMurray, J.P. (2002). Role of DRD2 and other dopamine genes in personality traits. In J. Benjamin, R.P. Ebstein, \& R.H. Belmaker (Eds.), Molecular genetics and the human personality. Washington, DC: American Psychiatric Publishing, Inc.

Coons, P.M. (1994). Confirmation of childhood abuse in child and adolescent cases of multiple personality disorder and dissociative disorder not otherwise specified. Journal of Nervous and Mental Disease, 182, 461-464.

Coons, P.M., Bowman, E.S., \& Milstein, V. (1988). Multiple personality disorder: A clinical investigation of 50 cases. Journal of Nervous and Mental Disease, 176, 519-527.

Dell, P.F., \& Eisenhower, J.W. (1990). Adolescent multiple personality disorder: A preliminary study of eleven cases. American Academy of Child and Adolescent Psychiatry, 29, 359-366.

Demitrack, M.A., Putnam, F.W., Rubinow, D.R., Pigott, T.A., Altemus, M., Krahn, D.D., \& Gold, P.W. (1993). Relation of dissociative phenomena to levels of cerebrospinal fluid monoamine metabolites and beta-endorphin in patients with eating disorders: A pilot study. Psychiatry Research, 49, 1-10.

Dragan, W.Ł., \& Oniszczenko, W. (2009). The association between dopamine D4 receptor exon III polymorphism and intensity of PTSD symptoms among flood survivors. Anxiety, Stress \& Coping, 22(5), 483-495.

Ebstein, R.P., Novick, O., Umansky, R., Priel, B., Osher, Y., Blaine, D., Bennett, E.R., Nemanov, L., Katz, M., \& Belmaker, R.H. (1996) Dopamine D4 receptor (D4DR) exon III polymorphism associated with the human personality trait of novelty seeking. Nature Genet ics, $12,78-80$.

Evren, C., Sar, V., \& Dalbudak, E. (2008). Temperament, character and dissociation among detoxified male inpatients with alcohol dependency. Journal of Clinical Psychology, 64(6), 717-727.

Fagan, J., \& McMahon, P.P. (1984). Incipient multiple personality in children Four cases. Journal of Nervous and Mental Disease, 172, 26-36.

Gillespie, N.A., Cloninger, C.R., Heath, A.C., \& Martin, N.G. (2003). The genetic and environmental relationship between Cloninger's dimensions of temperament and character. Personality and Individual Differences, 35, 1931-1946.

Grabe, H.J., Spitzer, C., Freyberger, H.J. (1999). Relationship of dissociation to temperament and character in men and women. The American Journal of Psychiatry, 156(11), 1811-1813.

Gray, J.A. (1970). The psychophysiological basis of introversion-extraversion. Behavioral Research and Therapy, 8, 249-266.

Hilgard, E.R. (1986). Divided consciousness: Multiple controls in human thought and action. New York: John Wiley \& Sons.
Hornowska, E. (2003). Temperamentalne uwarunkowania zachowania [Temperamental determinants of behavior]. Poznan: Bogucki. (in Polish)

Hornstein, N.L., \& Putnam, F.W. (1992). Clinical phenomenology of child and adolescent dissociative disorders. American Academy of Child and Adolescent Psychiatry, 31, 1077-1085.

Hulette, A.C., Freyd, J.J., \& Fisher, P.A. (2011). Dissociation in middle childhood among foster children with early maltreatment experiences. Child Abuse \& Neglect, 35, 123-126.

Jang, K.L., Paris, J., Zweig-Frank, H., \& Livesley, W.J. (1998). Twin study of dissociative experience. Journal of Nervous and Mental Disease, 186, 345-351.

Januszewski, A. (2009). Temperamentalne wskaźniki układów dopaminoraz serotoninergicznego a poczucie dolegliwości somatycznych w świetle wyników badań młodzieży [Temperamental indicators of dopamin- and serotonergic systems and a semse of somatic discomfort in the light of youth research]. In Janowski, K. \& Cudo, A. (Eds.). Czlowiek chory. Aspekty Biopsychospoleczne. [The sick man. Biopsychosocial aspects.] (Vol. 2, pp. 98-114). Lublin: Centrum Psychologii i Pomocy Psychologicznej. (in Polish)

Kennedy, F., Clarke, S., Stopa, L., Bell, L., Rouse, H., Ainsworth, C., Fearon, P., \& Waller, G. (2004). Towards a cognitive model and measure of dissociation. Journal of Behavior Therapy and Experimental Psychiatry, 35(25), 25-48.

Korzekwa, M.I., Dell, P.F., \& Pain, C. (2009). Dissociation and borderline personality disorder: An update for clinicians. Current Psychiatry Reports, 11, 82-88.

Laidlaw, T.M., Dwivedi, P., Naito, A., \& Gruzelier, J.H. (2005). Low selfdirectedness, mood, schizotypy and hypnotic susceptibility. Personality and Individual Differences, 39(2), 469-480.

MacKinnon, D.P., \& Dwyer, J.H. (1993). Estimating mediated effects in prevention studies. Evaluation Review, 17(2), 144-158.

Malhotra, A.K., Kestler, L.J., Mazzanti, C., Bates, J.A., Goldberg, T., \& Goldman, D. (2002). A functional polymorphism in the COMT gene and performance on a test of prefrontal cognition. American Journal of Psychiatry, 159, 652-654.

Mardaga, S. \& Hansenne, M. (2007). Relationships between Cloninger's biosocial model of personality and the behavioral inhibition/approach systems (BIS/BAS). Personality \& Individual Differences, $42,715-722$.

Merckelbach, H., Rassin, E., \& Muris, P. (2000). Dissociation, schizotypy, and fantasy proneness in undergraduate students. Journal of Nervous and Mental Disease, 188, 428-431.

Munafo, M.R., Yalcin, B., Willis-Owen, S.A., \& Flint, J. (2008). Association of the dopamine D4 receptor (DRD4) gene and approachrelated personality traits: Meta-analysis and new data. Biological Psychiatry, 63, 197-206.

Neale, M.C., \& Cardon, L.R. (1992). Methodology for genetic studies of twins and families. Dordrecht: Kluwer Academic Publishers.

Noble, E.P., Ozkaragoz, T.Z., Ritchie, T.L., Zhang, X., Belin, T.R., \& Sparkes, R.S. (1998). D2 and D4 dopamine receptor polymorphisms and personality. American Journal of Medical Genetics, 81, 257-267.

Oniszczenko, W., \& Rogucka, E. (1996). Diagnoza zygotyczności bliźniąt na podstawie Kwestionariusza Fizycznego Podobieństwa Bliźniąt. [The twins zygosity diagnosis by the means of Twins Physical Resemblance Questionnaire]. Przeglad Psychologiczny, 39, 151-160. (in Polish)

Pieper, S., Out, D., Bakermans-Kranenburg, M.J., \& van Ijzendoorn, M.H. (2011). Behavioral and molecular genetics of dissociation: The role of the serotonin transporter gene promoter polymorphism (5-HTTLPR). Journal of Traumatic Stress, 24(4), 373-380.

Plomin, R., DeFries, J.C., McClearn, G.E., McGuffin, P. (2008). Behavioral Genetics (5th edition). New York: Worth Publishers.

Pope, C.A., \& Kwapil, T.R. (2000). Dissociative experiences in hypothetically psychosis-prone college students. Journal of Nervous and Mental Disease, 188, 530-536.

Putnam, F.W. (1997). Dissociation in children and adolescents. New York: Guilford Press

Putnam, F.W., Gurof, J.J., Silberman, E.K., Barbar, L., \& Post, R.M. (1986). The clinical phenomenology of multiple personality disorder. A review of 100 cases. Journal of Clinical Psychiatry, 47, 285-293. 
Richman, H., \& Frueh, B.C. (1997). Personality and PTSD. II. Personality assessment of PTSD-diagnosed Vietnam veterans using Cloninger Tridimensional Personality Questionnaire (TPQ). Depression and Anxiety, 6, 70-77.

Ross, C.A. (1996). Dissociative identity disorder: Diagnosis, clinical features, and treatment of multiple personality. New York: John Wiley \& Sons.

Ruiz, M.A., Pincus, A.L., \& Ray, W.J. (1999). The relationship between dissociation and personality. Personality and Individual Differences, 27, 239-249.

Simeon, D., Knutelska, M., Smith, L., Baker, B.R., \& Hollander, E. (2007). A preliminary study of cortisol and norepinephrine reactivity to psychosocial stress in borderline personality disorder with high and low dissociation. Psychiatry Research, 149, 177-184.

Spiegel, D., \& King, R. (1992). Hypnotizability and CSF HVA levels among psychiatric patients. Biological Psychiatry, 31, 95-98.

Steiger, H., Richardson, J., Joober, R., Gauvin, L., Israel, M., Bruce, K.R., Ying Kin, N.M., Howard, H., \& Young, S.N. (2007). The 5HTTLPR polymorphism, prior maltreatment and dramatic-erratic personality manifestations in women with bulimic syndromes. Journal of Psychiatry and Neuroscience, 32(5), 354-362.
Strobel, A., Spinath, F.M., Angleitner, A., Riemann, R., \& Lesch, K.P. (2003). Lack of association between polymorphisms of the dopamine D4 receptor gene and personality. Neuropsychobiology, 47, $52-56$.

Szekely, A., Kovacs-Nagy, R., Banyai, E.I., Gosi-Greguss, A.C., Varga, K., Halmai, Z., Ronai, Z., \& Sasvari-Szekely, M. (2010). Association between hypnotizability and the catechol-O-methyltransferase (COMT) polymorphism. International Journal of Clinical and Experimental Hypnosis, 58(3), 301-315.

Waller, N.G., Putnam, F.W., \& Carlson, E.B. (1996). Types of dissociation and dissociative types: A taxometric analysis of dissociative experiences. Psychological Methods, 1(3), 300-321.

Waller, N.G., \& Ross, C.A. (1997). The prevalence and biometric structure of pathological dissociationin the general population: Taxometric and behavior genetic findings. Journal of Abnormal Psychology, 106, 499-510.

Van Ijzendoorn, M.H., \& Schuengel, C. (1996). The measurement of dissociation in normal and clinical populations: Meta-analytic validation of the Dissociative Experiences Scale (DES). Clinical Psychology Review, 16(5), 365-338. 